\title{
O significado dos olhos nas representações sociais de clientes transplantados de córnea e suas implicações para o cuidado de si
}

Recebido em: 13/02/2012

Aceito em: 27/09/2012

\author{
Ralrizônia Fernandes Sousa ${ }^{1}$ \\ Sílvio Éder Dias da Silva ${ }^{2}$ \\ Esleane Vilela Vasconcelos ${ }^{3}$ \\ Lucialba Maria Silva dos Santos ${ }^{4}$ \\ Vander Monteiro da Conceição ${ }^{5}$ \\ Jeferson Santos Araujo ${ }^{6}$
}

\begin{abstract}
Objetivou-se identificar o significado dos olhos nas representações sociais de clientes transplantados de córnea e suas implicações para o cuidado de si. Tratase de uma pesquisa descritiva qualitativa, adotando a Teoria das Representações Sociais na perspectiva de Moscovici. Fizeram parte deste estudo, 15 clientes submetidos a transplantes de córnea e que se encontravam em acompanhamento no Consultório de Oftalmologia do Ambulatório do Hospital Ophir Loyola, em Belém, PA. Os depoentes atribuíram significados diversos aos seus olhos, substanciados por sentimentos de tristeza e insatisfação, que contribuíram para mudanças significativas no cuidado de si. Há necessidade de se cogitar sobre o compromisso do enfermeiro com o cliente transplantado de córnea que, muitas vezes, encontra-se fragilizado, necessitando de um olhar mais atento.
\end{abstract}

Descritores: Enfermagem, Transplante de Córnea, Cuidado de Si.

\section{Eye on the meaning of social representations corneal transplantation customers and it's implications for the care of you}

The aim of this study was to identify the meaning of the eyes of customers in the social representations of corneal transplant and its implications for self-care. It is a descriptive and qualitative study, adopting the Social Representation Theory in the context of Moscovici. The sample comprised 15 clients who underwent corneal transplantation and were followed up in the office of the Ophthalmology Clinic of the Ophir Loyola Hospital, in Belem, Pará. The respondents attributed different meanings to their eyes; substantiated by feelings of sadness and dissatisfaction, that contributed to significant changes in self-care. There is need to think about the commitment of the nurse with the client cornea transplant, which often is fragile, requiring a closer look.

Descriptors: Nursing, Corneal Transplantation, Self-care.

\section{Los ojos sobre el significado de los clientes representataciones sociales transplante de córnea y sus conscuencias para el cuidad de usted} El objetivo fue identificar el significado de los ojos de los clientes en las representaciones sociales de trasplante de córnea y sus implicaciones para el autocuidado. Se trata de un estudio descriptivo cualitativo, adoptando laTeoría de las Representaciones Sociales en el contexto de Moscovici. La muestra es compuesta por 15 clientes que se sometieron a trasplante de córnea que se siguió en la oficina de la Clínica de Oftalmología del Hospital Ophir Loyola, en Belem, Pará. Los encuestados atribuyen diferentes significados a sus ojos, motivada por sentimientos de tristeza e insatisfacción, que han contribuido a cambios significativos en el auto-cuidado. Hay que pensar en el compromiso de la enfermera con el trasplante de cornea del cliente, que a menudo es frágil, lo que requiere una mirada más cercana.

Descriptores: Enfermería, Trasplante de Córnea, Cuidar de si.

\section{INTRODUÇÃO}

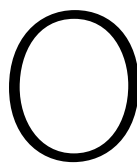
transplante de córnea é um dos procedimentos cirúrgicos mais importantes da oftalmologia pelo que representa na recuperação visual de um indivíduo na sociedade $^{(1)}$. Dados do primeiro semestre de 2009 contabiliza-se que foram realizados 6.151 transplantes de córnea no Brasil e 1.251 transplantes de rim. No estado do Pará, no mesmo período, realizaram-se 62 transplantes de córnea e nove transplantes de rim. Esse tipo de procedimento ocorre em maior quantidade que o de órgãos por diversos motivos. As córneas, os tecidos e ossos podem ser captados de um doador até seis horas após sua morte, enquanto os órgãos sólidos necessitam necessariamente ser retirados de doadores em morte encefálica ${ }^{(2)}$.

1 Enfermeira. Licenciada Plena e Bacharel em Enfermagem e Obstetrícia pela Faculdade de Enfermagem da Universidade Federal do Pará - FAENF/UFPA. E-mail: rjna2005@ hotmail.com

2 Enfermeiro. Doutor em Enfermagem pelo Dinter UFPA/UFSC, vinculado ao Núcleo de Pesquisa Gehces - Grupo do Estudo de História do Conhecimento da Enfermagem e Saúde/UFSC. Professor Assistente da Faculdade de Enfermagem da UFPA.

3 Enfermeira. Atua no Hospital Ophir Loyola e da Coordenação de Estadual de Atenção Oncológica da Secretária de Estado de Saúde Pública do Pará - SESPA.

4 Enfermeira. Licenciada Plena e Bacharel em Enfermagem e Obstetrícia pela Faculdade de Enfermagem da Universidade Federal do Pará- FAENF/UFPA.

5 Enfermeiro. Licenciado Pleno e Bacharel em Enfermagem e Obstetrícia - FAENF/UFPA Especialista em Integralidade da Atenção Oncológica - IEPS.

6 Enfermeiro. Licenciado Pleno e Bacharel em Enfermagem pela Faculdade de Enfermagem da Universidade Federal do Pará - FAENF/UFPA 
Ressalta-se a importância de conhecer as representações sociais que os clientes transplantados de córnea têm sobre o transplante e as implicações dessas representações para o cuidado de si, uma vez que possibilitará a reformulação de preconcepções e a elaboração de novos conceitos sobre o transplante. Assim sendo, transplante de córnea, como um dos procedimentos cirúrgicos de maior importância na oftalmologia moderna, é merecedor de grande atenção da enfermagem, que pode contribuir para o resultado satisfatório da cirurgia por meio de ações educativas e orientações no que se refere a todo o mecanismo que envolve o pré e o pós-operatório do transplante, uma vez que o conhecimento desses dois momentos é primordial para o sucesso do procedimento ${ }^{(3)}$.

Considera-se que a contribuição deste estudo para a enfermagem é de grande relevância, uma vez que, durante os contatos estabelecidos com os clientes transplantados, percebemos a importância de direcionar um olhar mais atento a eles, pois muitos se encontravam fragilizados frente à situação vivenciada. A percepção quanto a fragilidade psicossocial dos clientes traz à tona a necessidade de se realizar um acompanhamento adequado a esses sujeitos, que perpasse pela compreensão de suas fragilidades e anseios.

\section{OBJETIVO}

Identificar o significado dos olhos nas representações sociais de clientes transplantados de córnea e suas implicações para o cuidado de si.

\section{PERCURSO METODOLÓGICO}

Este estudo é do tipo qualitativodescritivo, adotando como aporte conceitual a Teoria das Representações Sociais na perspectiva de Serge Moscovici, que permite compreender o indivíduo como um ser psicossocial, que se apodera de um conhecimento, acrescenta seu toque pessoal e o compartilha com o seu grupo de pertença, ou seja, o sujeito possui uma história pessoal com determinantes sociais e culturais ${ }^{(3)}$.

A pesquisa foi realizada no município de Belém, estado do Pará. Os sujeitos do estudo foram 15 clientes submetidos a transplantes de córneas que se encontravam em acompanhamento pós-transplante no Consultório de Oftalmologia do Ambulatório do Hospital Ophir Loyola (HOL). O projeto foi aprovado pelo Comitê de Ética em Pesquisa da Universidade Federal do Pará sob o número 145/10 - CEPS ICS/UFPA.

Buscou-se desdobrar a análise temática em três etapas: a primeira é a pré-análise, que consistiu na seleção e organização do material; a segunda é a exploração do material; e a terceira, o tratamento dos dados. Ao fim da análise, chegou-se às seguintes categorias temáticas: Olhos: parte essencial do corpo humano;
Olhos: reflexos de tristeza; Reflexões para o cuidado de si a partir das representações sociais de clientes transplantados de córnea sobre o cuidado com os olhos.

\section{RESULTADOS E DISCUSSÃO}

\section{Olhos: parte essencial do corpo humano}

A partir das falas dos depoentes, o estudo permitiu identificar significados diversos para os seus olhos, permeados por simbolismos e construídos ao longo de todo o processo do acometimento da doença e da realização do transplante de córnea e a relevância desses sentidos para o cuidado de si.

Para Ferreira ${ }^{(4)}$ o homem não se dá conta de um órgão antes dele the doer; não pensando em seu corpo enquanto tem saúde. Mas a doença não o inventa. Ela apenas atua como um despertar da existência do corpo.

"(...) Ah, várias coisas, os olhos significam uma parte principal do corpo humano que sem eles nós não vemos (...)."(E9)

"(...) então o fato de perder a visão de um olho parece que eu perdi uma perna, um braço (...)". (E7)

A partir das falas, pode-se inferir que as representações sociais dos depoentes foram fomentadas por suas vivências relacionadas à possibilidade da perda da visão, o que os favoreceu na construção de seus conceitos quanto à idealização da importância dos olhos. Ressalta-se que uma representação social existe porque constantemente os sujeitos necessitam de informações sobre o mundo que os circunda, para poder, assim, adequarem-se a ele; precisam ainda saber como se portar diante das especificidades, identificando e solucionando intercorrências que porventura se façam presentes. É isso que impulsiona os sujeitos na elaboração do conhecimento do senso comum.

Segundo Shealy e Myss ${ }^{(5)}$, cada pessoa contribui diretamente, de forma consciente ou não, para a concepção da própria realidade, incluindo a própria saúde.

Os relatos dos depoentes inseridos nesta categoria nos permitiram compreender que os mesmos, ao se encontrarem com os olhos afetados por uma doença e com a indicação e efetivação do transplante de córnea, alicerçaram representações únicas e relevantes no que diz respeito à importância dos olhos saudáveis para a manutenção da vida e do bem-estar.

\section{Olhos: reflexos de tristeza}

Existe na vida do ser humano a tendência natural em manter todos os seus aspectos em constante estado de equilíbrio como se fossem uma rede. Na concepção de Cyrillo(6), a alteração em qualquer um desses aspectos pode eventualmente desarticular temporária ou permanentemente a vida do indivíduo e, dependendo de como isso ocorre, pode haver consequências de maior ou menor gravidade. 
Evidenciou-se em algumas falas que a perda da visão tende a ser recebida como um cataclismo onde os significados da cegueira e da vida não raramente dançam juntos, onde a noção de tragédia, amiúde, encontra guarida.

"(...) Porque, quando eu perdi a minha visão... Ah, eu fiquei muito triste, eu fiquei desesperada, eu quase quebrava o consultório do médico... eu ainda me emociono quando falo do assunto, porque pra mim foi muito triste eu perder a minha visão que eu precisava tanto (...)". (E4)

"(...) Eu não existia mais, totalmente sem vida. Eu não saía de casa. Passei um mês deitada sem me levantar da cama pra nada. Entrei totalmente em uma tristeza profunda (...)". (E1)

A partir das falas, percebemos que o elemento tristeza permeia a trajetória inicial dos pacientes transplantados de córnea ao se depararem com a possibilidade da perda da visão, sendo esse sentimento expresso através de representações latentes, coabitadas por situações traumáticas e frustradoras, pelo isolamento social e pela perda de disposição para com a vida.

Vale ressaltar que tais representações se coadunam com estudos desenvolvidos por Stoppe e Segal ${ }^{(7)}$, nos quais os autores simbolizam a depressão no senso comum ancorada nos sentimentos de tristeza profunda, desamparo e apatia, não estando necessariamente relacionada a um distúrbio ou doença, mas sim, enquanto esfera de pensamentos e/ou emoções desagradáveis que invadem e se instalam na mente dos indivíduos.

Um aspecto relevante, abordado nas falas de alguns depoentes, refere-se ao sentimento de tristeza relacionado ao aspecto estético dos olhos, devido ao adoecimento dos mesmos.

"(...) Eu chorava muito ao ver meu olho daquela forma que ficou depois do ocorrido (...)". (E9)

"(...) Chorava muito quando me olhava no espelho e via o estado que estava ficando o meu olho (...)". (E13)

"(...) Quando eu procurei o oftalmologista e ele me falou que eu tinha perdido a visão... eu só fiquei pensando como meus olhos iam ficar feios, ia sofrer preconceito do povo, comentários (...)". (E8)

Observou-se que, ao configurarem seu corpo como estando alterado esteticamente, os depoentes o fazem demonstrado sentimentos de tristeza, medo e preocupação com o aspecto visual dos olhos e a forma como irão ser recebidos no convívio social, pois acreditam que já não se enquadram nos padrões de normalidade, valorizados pela sociedade.

Conforme Cyrillo ${ }^{(6)}$, existem perdas que, por suas características, têm a tendência de provocar grandes alterações na vida das pessoas. Além do problema óbvio da alteração visual, existe uma consideração na qual, para algumas pessoas, é intolerável a imagem corporal defeituosa, sendo uma deformidade facial considerada muito maior que qualquer outra ${ }^{(8)}$.

Na perspectiva de Tavares $^{(9)}$, o desenvolvimento da imagem corporal está intimamente ligado à estruturação da identidade no seio de um grupo social. No estudo da imagem ou representação do corpo, há uma ênfase coletiva, relacionada às opiniões e ao senso comum, teorizada por Moscovici ${ }^{(10)}$.

A partir da panorâmica extraída dos depoimentos, foi possível observar que, ao se deparar com a realidade da doença instalada nos olhos e suas complicações, esses clientes estruturaram suas representações sociais a partir de concepções formuladas em um contexto sócio-histórico, onde o corpo é percebido como um lugar da identidade humana, sendo o mesmo instrumento de inserção no grupo social e no qual qualquer alteração em sua anatomia pode gerar uma exclusão social e também uma desigualdade de oportunidades.

\section{Reflexões para o cuidado de si a partir das representações sociais de clientes transplantados de córnea sobre o cuidado com os olhos}

Os relatos nos mostraram uma significativa diferença nas atitudes de cuidados com os olhos em dois momentos distintos: antes do adoecimento dos olhos e depois da realização do transplante.

Segundo Maia ${ }^{(11)}$, o cuidado de si pode ser compreendido como a construção de ações de cuidado direcionadas a si mesmo a partir do despertar da conscientização no que se refere à influência de hábitos pessoais sobre o seu próprio bem-estar total.

$\mathrm{Na}$ concepção de Boff(12), o cuidado é uma atitude intrínseca da natureza humana, e uma postura frente ao cuidado pode provocar preocupações, inquietações e senso de responsabilidade com o outro e consigo mesmo.

O descuidado pode ser compreendido como toda ação não valorativa empregada a algo ou alguém, nesse caso, a saúde. Boff ${ }^{(12)}$ afirma que o descuidado ou o des-zelo com a saúde aflora quando o individuo nega a própria essência de ser cuidado, tornando-se cruel consigo mesmo, tendo como resultado o processo de saúde e doença alterado, e consequentemente alterando o seu bem-estar e sua qualidade de vida.

Reportando-se à fala dos depoentes, observou-se que os mesmos não mantinham uma prática de cuidados diários com a visão como um cuidado à sua saúde, uma vez que não se preocupavam com os olhos.

"(...) Antes do acidente, não ligava muito (...)". (E13)

"(...) Eu não dava a mínima importância aos meus olhos e hoje vejo o quanto eles são importantes (...)". (E12)

"(...) Antes de realizar o transplante eu não tinha nenhum cuidado com meus olhos (...)". (E8)

Na concepção deWaldow ${ }^{(13)}$, o cuidado configura-se como uma postura estética frente ao mundo, podendo ser compreendida como uma condição subjetiva da existência do homem. Uma forma de se relacionar, de ser e consequentemente de viver, em 
que os indivíduos procuram harmonizar os significados e desejos de bem-estar em relação às suas próprias ações em função do bem-estar de outros.

O cuidado de si e o descuidado conseguem, englobam por diversas práticas adquiridas durante o processo de socialização do conhecimento entre os grupos, fato que, para Moscovici ${ }^{(14)}$, substancia o fenômeno das representações sociais.

Observou-se que a realização do transplante de córnea despertou nos sujeitos mudanças comportamentais, relacionadas à importância do cuidado com os olhos. O cuidar de si após o transplante tornou-se presente e primordial na vida desses indivíduos.

"(...) Agora, em tudoqueeufaçotenhoquetermaiscuidado, mais higiene. Porque, devido a esse problema, eu tenho que ter mais higiene com os olhos, com os óculos. Precaução com tudo (...)". (E6)

"(...) Ah, procuro me cuidar mais, diminuí a quantidade de cigarros que fumava no dia, faço atividade física..., faço os cuidados de higiene, uso óculos de proteção solar... enfim tento cuidar da melhor forma de mim e da vista (...)". (E10)

Identificou-se nas falas descritas que o cuidado com a saúde dos olhos foi descoberto pelos sujeitos da pesquisa após a perspectiva da perda da visão, condição socialmente carregada com estigmas, medo e representação de limitações da vida. Esse cuidado de si foi interiorizado como necessário, ficando caracterizada a construção de um universo permeado por ações de cuidados, como um modo de manutenção e precaução com a saúde dos olhos.

Ao longo de sua existência, o ser humano desenvolve o potencial pelo cuidado que, normalmente, se constrói de acordo com a cultura, as crenças, os valores e as vivências advindos do contexto ambiental em que cada ser está inserido. Assim, para Erdmann ${ }^{(15)}$, o ser humano busca o cuidado na tentativa de sobrevivência, e esse cuidado provavelmente constitui-se na resposta às necessidades manifestas, criadas ou provocadas por inúmeros fatores nos momentos em que a sua construção se faz relevante para o bem-estar.

\section{CONSIDERAÇÕES FINAIS}

Evidenciou-se que as etapas do processo de transplante de córnea foram cercadas por uma diversidade de significados, os quais foram detalhadamente retratados pelos sujeitos do estudo ao relembrar os instantes de incerteza, tensão e sofrimento vividos e a aglutinação desses sentidos na construção de ações de cuidado de si, permeadas por sentimentos diversos.

A partir da realização deste estudo procurou-se levantar algumas questões que possibilitem um novo olhar para o cliente transplantado de córnea, bem como para cogitar-se sobre o compromisso do enfermeiro, criando, a partir daí, novas visões e estratégias para o lidar com essa clientela, que muitas vezes encontra-se fragilizada, necessitando de um olhar mais atento. A doação de órgãos e tecidos, assim como os transplantes de uma forma geral, ainda é temática de maior domínio da medicina e necessita de um maior entendimento dos processos vivenciados pelos sujeitos integrantes desse universo como forma de expressar em sua construção, no senso comum, a melhor maneira para se abordar a temática.

\section{Referências}

1. Calix Netto MJ. Principais indicações de transplante penetrante de córnea em um serviço de referência no interior de São Paulo (Sorocaba - SP, Brasil) [Internet]. [citado em 2010 Jun 15]. Disponível em: http://www.scielo.br/scieloOrg/php/ citedScielo.php?pid=S007\&lang=en

2. Ministério da Saúde (BR). Notícias Transplantes. Transplantes de órgãos crescem 24,3\% Brasília [Internet]. [citado 2010 Jun 12]. Disponível em: http://portal.saude.gov.br/portal/aplicacoes/noticias/default. cfm?pg=dspDetalheNoticia\&id_area=124\&CO_NOTICIA=10592 3. Moscovici S. Investigações em psicologia social. 2ª ed. Petrópolis: Vozes; 2007. 4. Ferreira V. Questionação a Foucault e algum estruturalismo. In: Foucault M. As palavras e as coisas. Lisboa: Edições 70; 2002. p. 21-46.

5. Shealy CN, Myss CM. Medicina intuitiva - reações emocionais, psicológicas e espirituais que propiciam a saúde e a cura. São Paulo: Cultrix; 1993. 6. Cyrillo PI. Aspectos psicológicos relacionados aos portadores de lesões oculares e a utilização de prótese. In: Fonseca EPD. Prótese ocular. São Paulo: CIP; 1987. p. 181-7.

7. Stoppe A, Segal A. Depressão - atualização neuropsiquiatria. São Paulo: Lemos; 1998.
8. Lubkin V. Psychological considerations. In: Stwart WB. Plastic surgery.

California: San Francisco; 1984. p. 42-4.

9. Tavares MCGC. Imagem corporal: conceito e desenvolvimento. Barueri: Manole 2003.

10. Moscovici S. A representação social da psicanálise. Rio de Janeiro: Zahar; 1978.

11. Maia AR. Princípios de cuidar. In: Reibnitz KS, Horr J, Souza ML, Spríccigo JS (organizadores). O processo de cuidar, ensinar e aprender o fenômeno das drogas: políticas de saúde, educação e enfermagem. Florianópolis: PEN/UFSC; 2003. v. 2, p. 49-62.

12. Boff L. Saber cuidar. Ética do humano - compaixão pela terra. Petrópolis: Vozes; 1999

13. Waldow VR. Cuidado humano: o resgate necessário. 3a ed. Porto Alegre: Sagra Luzzatto; 2001.

14. Moscovici S. Representações sociais: investigações em psicologia social. Petrópolis: Vozes; 2009.

15. Erdmann AL. O sistema de cuidados de enfermagem: suas organizações nas instituições de saúde. Texto Contexto Enferm. 1998;7(2):52-69. 